\title{
A formação dos ministros da educação no Brasil e o recorte de gênero - 1930 a 2020: políticas públicas de gestão
}

\section{The formation of ministers of education in Brazil and gender cutting - 1930 to 2020: public management policies}

Maria Cristina das Graças Dutra Mesquita ${ }^{1 *}$, Renato Barros de Almeida ${ }^{1}$, Sylvana de Oliveira Bernardi Noleto ${ }^{2}$

\begin{abstract}
RESUMO
O artigo traz a relação dos Ministros da Educação no Brasil entre os anos 1930 e 2020, com o intuito de discutir qual a formação inicial dos profissionais que assumiram o órgão federal da educação brasileira e se a formação em cursos de licenciatura aparece como indicativo nas escolhas destas pessoas para o cargo principal da educação no Brasil. Discute-se ainda como se dá a presença da mulher neste cargo, no mesmo período. Trata-se de um estudo bibliográfico, inserido no campo das políticas públicas. Concluiu-se que a maior parte dos Ministros teve como formação o curso de bacharel em Direito, além de outras áreas como Medicina, Economia, Administração, Engenharia. Em todo o período analisado o Ministério da Educação teve apenas uma mulher na sua gestão. O estudo revelou pouca permanência dos Ministros nos cargos, exceto Paulo Renato Souza e Fernando Haddad.
\end{abstract}

Palavras-chave: Políticas Públicas; Ministros da Educação; Formação, Gênero

\section{ABSTRACT}

The article presents the Brazilian Education Ministers's list between 1930 and 2020, in order to discuss the initial training of professionals who took over the Brazilian's education federal agency and if the training in degree with a teaching diploma courses appears as an indicative in these people choices for Brazil's education main job. It is also discussed how the presence of women in this position occurs, in the same period. This is a bibliographic study, inserted in the field of public policies. It was concluded that most of the Ministers had a bachelor's degree in Law, beyond other areas like Medicine, Economics, Administration, Engineering. In the entire period analyzed, the Ministry of Education had only one woman in its management. The study revealed little permanence of Ministers in office, with rare exception, case of Ministers Paulo Renato Souza and Fernando Haddad, the first remained the eight years of Fernando Henrique Cardoso's administration and the second remained seven years, six years in Lula's government and one year in Dilma's government, when he did the governments transition.

Keywords: Public policy; Ministers of Education; Formation; Gender

1 Pontifícia Universidade Católica de Goiás/Escola de Formação de Professores e Humanidades/PPGE. *E-mail: mcristinadm@yahoo.com.br ; renatobalmeida@hotmail.com

2 Universidade Estadual de Goiás/PPGE - Unidade Universitária de Inhumas. E-mail: sylvanabn@ueg.br 


\section{INTRODUÇÃO}

A questão que nos interessa evidenciar e compreender neste artigo é qual a formação inicial dos Ministros da Educação do Brasil e se a formação em cursos de licenciatura aparece como indicativo nas escolhas destas pessoas para o cargo principal da educação no Brasil. Por fím, como se dá a presença da mulher no mesmo período. Nosso objetivo é analisar a relação da formação inicial dos Ministros da Educação no Brasil e a presença de mulheres no cargo, no período de 1930 até 2020, quando iniciamos uma nova fase na organização do Estado brasileiro, conhecida como Brasil República.

A formação pedagógica para aqueles que pretendem atuar no campo da educação é algo desejável. A LDB em vigor, $n^{\circ}$ 9.394/96, no Art. 61, Parágrafo único diz que a formação dos profissionais da educação deve atender às especificidades do exercício de suas atividades, a gestão está entre elas. A Resolução do Ministério da Educação (MEC) $\mathrm{n}^{\circ} 2$ de 2015, que define as Diretrizes Curriculares Nacionais para a formação inicial em nível superior (cursos de licenciatura, cursos de formação pedagógica para graduados e cursos de segunda licenciatura) e para a formação continuada, contempla, no $\S 2^{\circ}$ do Art. $3^{\circ}$, que a educação se efetiva "por meio de processos pedagógicos [...] nas políticas, na gestão, nos fundamentos e nas teorias sociais e pedagógicas para a formação ampla e cidadã e para o aprendizado nos diferentes níveis, etapas e modalidades de educação básica”. Neste sentido, entendendo que a educação básica é a única assegurada a todos enquanto direito constitucional, torna-se preponderante que os que vão atuar na gestão e coordenação da educação brasileira conheçam-na de forma radical.

Consta em nossa Constituição Federal de 1988, que é tarefa do Estado a responsabilidade pela organização de sistemas públicos de ensino. A educação é direito de todos e, por conseguinte, sua oferta deve ser pública, conduzida pelo Estado por meio de políticas educacionais que garantam igualdade de condições e oportunidades a todos. Entretanto, como sabemos que as políticas públicas não são neutras, significa dizer que as ações que objetivam estas políticas estão marcadas pelo interesse de determinado governo e pela sua compreensão de sociedade.

Embora estudiosos do campo da educação afirmem que o Brasil não possui um sistema nacional de educação, mesmo tendo leis que façam referência à implantação desse sistema, é indiscutível o papel do MEC na condução das discussões que possibilitem a construção de um sistema de educação nacional. 
Conforme Saviani (1997), para assumir a função pública de maior autoridade na esfera da educação é preciso ter conhecimento dos seus problemas inclusive aqueles que persistem em todo o país, conhecer as estruturas das diferentes realidades existentes e por fim, com igual importância, assumir uma teoria da educação que oriente a elaboração e implementação de políticas educacionais.

\begin{abstract}
No planejamento educacional, o desenho do horizonte a alcançar é dada pela concepção de educação adotada, que se fundamenta na concepção de pessoa humana e sociedade, vale dizer, de cidadania. Concepção que orienta as políticas educacionais e orienta a direção a seguir, ou seja: as diretrizes do plano e as metas a seguir (BORDIGNON, 2014, p. 31).
\end{abstract}

Esta tarefa é intrínseca às funções do Ministério da Educação que tem por atribuição, formular e avaliar a política nacional de educação, zelar pela qualidade do ensino, velar pelo cumprimento da legislação educacional e assegurar a participação da sociedade no aprimoramento da educação brasileira. Conforme descrito no site do $\mathrm{MEC}^{3}$, sua competência está ligada a temas como a política nacional de educação, da educação infantil, a educação em geral, compreendendo o ensino fundamental, o ensino médio, o ensino superior, a educação de jovens e adultos, a educação profissional, a educação especial e a educação a distância, a avaliação, informação e pesquisa educacional, a pesquisa e extensão universitária, o magistério e a assistência financeira a famílias carentes para a escolarização de seus filhos ou dependentes.

É a partir da compreensão da importância do MEC na condução das políticas públicas para a educação nacional que iremos observar a formação dos seus gestores públicos no período 1930-2020 e buscar compreender as relações políticas implícitas nestas indicações ao cargo.

\title{
1. MINISTÉRIO DA EDUCAÇÃO: PERÍODO GETÚlIO VARGAS 1930- 1945
}

A educação no Brasil no período que antecede a chegada de Getúlio Vargas ao poder não apresenta muitos avanços. Considerando que a economia se baseava no extrativismo (período Colônia e Império), não havia interesse político governamental em oferecer educação para todos. As propostas para a educação no Brasil Império para muitos historiadores foram consideradas um fracasso:

Para tal situação contribuem tanto a ausência de infraestrutura institucional para apoiar sua operacionalização, quanto a indiferença política das elites,

3 Consulta feita ao site https://www.gov.br/mec/pt-br em 25 de janeiro de 2021. 
preocupadas pincipalmente em manter condições favoráveis à sua hegemonia econômica e social. Por esta razão, as propostas do período configuram-se como "reformas que não mudam" (VIEIRA e FARIAS, 2011, p. 77).

No período seguinte, a partir de um intenso período de disputas políticas, na configuração da República em 1889, o cenário político, econômico e social pouco se altera. Nesse período, de instauração de um novo modelo de Estado e uma nova forma de governo, a base econômica ainda se centrava na agricultura e pecuária e a organização política era traçada por meio da conhecida política do café com leite ${ }^{4}$. A necessidade de mão de obra qualificada passa a ser discutida em alguns estados, onde algumas reformas aconteceram: "São Paulo, Rio de Janeiro, Minas, Pernambuco, entre outros, protagonizaram iniciativas nesse sentido. [...] De modo geral, estas ações incidiram sobre a escola primária e a formação de seus professores" (VIEIRA e FARIAS, 2011, p. 98).

O pensamento revolucionário iniciado por Anísio Teixeira, Lourenço Filho, Fernando Azevedo, Francisco Campos entre outros notáveis, nas primeiras décadas do século XX, será decisivo para mudanças mais consistentes na educação brasileira. Data de 1932 a publicação do Manifesto dos Pioneiros da Escola Nova, que defende o acesso à população ao ensino básico, alicerçado em ideais liberais. Vinte e seis intelectuais da época são signatários do documento e, entre estes, apenas três mulheres: Armanda Álvaro Alberto (1892-1974), educadora e militante social; Cecília Meireles (1901-1964) professora, poetisa e pintora; Noemy Marques da Silveira (1902-1980), professora primária e posteriormente coordenadora do Serviço de Psicologia Aplicada em São Paulo.

Apesar da influência progressista e da defesa de uma educação comum para homens e mulheres, conforme expresso no Manifesto, a presença da mulher frente a cargos políticos diretamente ligados à gestão educacional não se realiza.

Em seu governo, Getúlio Vagas (1930 - 1945), que mais tempo permaneceu no poder, não indicou mulher para ocupar o cargo de Ministro/a da Educação, conforme podemos evidenciar no Quadro 1, que segue:

4 A política café com leite consistia na alternância presidencial entre os políticos de São Paulo (principal produtor de café) e de Minas Gerais (produtor de leite), resultante do domínio do poder econômico e político das oligarquias rurais, obtido principalmente a partir da exportação de café. 


\section{Quadro 1: Ministros da Educação e Saúde - Brasil -1930- 1945}

\begin{tabular}{|c|c|c|c|c|}
\hline Nome & Início & Fim & Presidente & Formação \\
\hline $\begin{array}{c}\text { Francisco } \\
\text { Campos }\end{array}$ & $6 / 12 / 1930$ & $31 / 08 / 1931$ & \multirow{5}{*}{$\begin{array}{l}\text { Getúlio } \\
\text { Vargas }\end{array}$} & $\begin{array}{l}\text { Advogado } \\
\text { Professor }\end{array}$ \\
\hline $\begin{array}{l}\text { Belisário } \\
\text { Penna } \\
\text { (interino) }\end{array}$ & $16 / 09 / 1931$ & $1 / 12 / 1931$ & & Médico Sanitarista \\
\hline $\begin{array}{c}\text { Francisco } \\
\text { Campos }\end{array}$ & $2 / 12 / 1931$ & $15 / 09 / 1932$ & & $\begin{array}{l}\text { Advogado } \\
\text { Professor }\end{array}$ \\
\hline $\begin{array}{c}\text { Washington } \\
\text { Ferreira Pires }\end{array}$ & $16 / 09 / 1932$ & $23 / 07 / 1934$ & & $\begin{array}{c}\text { Médico } \\
\text { Neurologista }\end{array}$ \\
\hline $\begin{array}{l}\text { Gustavo } \\
\text { Capanema }\end{array}$ & $23 / 07 / 1934$ & $30 / 10 / 1945$ & & Advogado \\
\hline $\begin{array}{c}\text { Raul Leitão da } \\
\text { Cunha }\end{array}$ & $30 / 10 / 1945$ & $31 / 01 / 1946$ & $\begin{array}{c}\text { José } \\
\text { Linhares }\end{array}$ & Médico \\
\hline
\end{tabular}

Fonte: Galeria de Ministros

(www.gov.br/mec/pt-br/acesso-a-informacao/institucional/galeria-deministros?b_start:int=40). Acesso em 26, jan. 2021.

Foi no ano de 1930, por força do Decreto n 19.402 de 14 de novembro, que Getúlio Vargas criou uma Secretaria de Estado com a denominação de Ministério dos Negócios da Educação e Saúde Pública. Entre as atribuições do novo Ministério constam o estudo e despacho de todos os assuntos relativos ao ensino, saúde pública e assistência hospitalar, conforme Art. $2^{\circ}$. do referido Decreto. Nessa configuração a educação ficou subsumida em um Ministério que divide as atenções e ações entre educação e saúde.

Somente em 1937, com a publicação da Lei no 378 de 13 de janeiro é que, ao se estabelecer uma ampla reforma e estruturação do sistema educacional brasileiro, o então Ministério é redefinido como Ministério da Educação e Saúde Pública.

Francisco Campos, o primeiro ministro da educação brasileira tem formação inicial em nível superior o curso de Direito, concluído em 1914, na Faculdade Livre de Direito em Belo Horizonte e dividiu sua carreira como advogado, professor e político. Teve uma breve interrupção no cargo de Ministro quando é substituído por Belisário Penna, médico sanitarista. Francisco Campos retorna ao cargo ficando até setembro de 1932 quando sai do governo para se dedicar à política, em busca de uma cadeira na Assembleia Nacional Constituinte, sem sucesso.

Washington Ferreira Pires, concluiu o curso de medicina em 1914, pela Faculdade de Medicina do Rio de Janeiro. Ficou no Ministério por quase dois anos. Sua biografia destaca-se pela presença no campo político, tendo sido Deputado Estadual (19231930), Deputado Federal (1935-1937), após sua passagem pelo Ministério da Educação 
e Saúde. Tendo em vista a natureza da criação deste Ministério, não é difícil entender a presença de médicos na condução das políticas públicas do governo federal, marcadamente por ações de saúde pública, incluindo a presença do Dr. Raul Leitão da Cunha, formado em 1903, pela Faculdade de Medicina do Rio de Janeiro, em um período curto de três meses.

No período compreendido entre 1934 a 1945, o Ministério da Educação e Saúde é ocupado pelo advogado Gustavo Capanema que bacharelou-se em Direito em dezembro de 1924 pela Faculdade de Direito de Minas Gerais. Assim como os seus antecessores, ingressou na carreira política sendo vereador em Pitangui- MG e presidente de Minhas Gerais (cargo equiparado ao de governador) de 5 de setembro de 1933 a 15 de dezembro de 1933. Em 23 de julho de 1934 assume o Ministério da Educação e Saúde do governo de Getúlio Vargas permanecendo até 30 de outubro de 1945.

\section{PERÍODO POPULISTA - MINISTROS DA EDUCAÇÃO E SAÚDE - 1945- 1964}

No período conhecido como populista, que vai de 1945 até início de 1964, o Brasil teve sete Presidentes da República e vinte e dois Ministros da Educação e Saúde. Há que ser registrada a curta passagem de Carlos Luz na presidência, de 8 de novembro de 1955 a 11 de novembro de 1955, em decorrência do afastamento de Café Filho por problemas de saúde. Nos seus três dias como presidente não nomeou Ministro da Educação, permanecendo no cargo Cândido Mota Filho.

Dos vinte e dois Ministros, seis foram interinos e tiveram uma curta passagem pelo Ministério. Nenhuma mulher esteve à frente da pasta nestes 19 anos.

Neste período também ocorreu alteração na denominação do Ministério. Em 25 de julho de 1953, Getúlio Vargas sanciona a Lei $\mathrm{n}^{\circ} 1.920$ que cria o Ministério da Educação e Cultura - MEC. Cabe destacar que a educação passou a ser atribuição exclusiva da pasta somente em 1995. período.

O Quadro 2, a seguir, traz a relação dos Ministros da Educação e Saúde no 
Quadro 2: Ministros da Educação e Saúde - Brasil -1946- 1964

\begin{tabular}{|c|c|c|c|c|}
\hline Nome & Início & Fim & Presidente & Formação \\
\hline $\begin{array}{l}\text { Ernesto de Sousa } \\
\text { Campos }\end{array}$ & $31 / 01 / 1946$ & $6 / 12 / 946$ & \multirow{4}{*}{ Gaspar Dutra } & Médico \\
\hline Clemente Mariani & $6 / 12 / 1946$ & $15 / 05 / 1950$ & & Advogado/Banqueiro \\
\hline $\begin{array}{l}\text { Eduardo Rios Filho } \\
\text { (interino) }\end{array}$ & $15 / 05 / 1950$ & $4 / 08 / 1950$ & & Político \\
\hline Pedro Calmon & 4/08/1950 & $31 / 05 / 1951$ & & Advogado/Professor \\
\hline $\begin{array}{l}\text { Ernesto Simões } \\
\text { Filho }\end{array}$ & $31 / 05 / 1951$ & $25 / 05 / 1953$ & \multirow{4}{*}{ Getúlio Vargas } & Jornalista \\
\hline $\begin{array}{l}\text { Péricles Madureira } \\
\text { de Pinho (interino) }\end{array}$ & 26/05/1953 & $24 / 06 / 1953$ & & Servidor Público \\
\hline Antônio Balbino & $25 / 06 / 1953$ & $2 / 07 / 1954$ & & Advogado \\
\hline Edgard Santos & 6/07/1954 & 24/08/1954 & & Médico \\
\hline Edgard Santos & $24 / 08 / 1954$ & $2 / 09 / 1954$ & \multirow{2}{*}{ Café Filho } & Médico \\
\hline Cândido Mota Filho & 2/09/1954 & $17 / 11 / 1955$ & & Advogado/Professor \\
\hline Abgar Renault & $24 / 11 / 1955$ & $31 / 01 / 1956$ & Nereu Ramos & Professor \\
\hline $\begin{array}{c}\text { Clóvis Salgado da } \\
\text { Gama }\end{array}$ & $31 / 01 / 1956$ & $30 / 04 / 1956$ & \multirow{8}{*}{$\begin{array}{l}\text { Juscelino } \\
\text { Kubitschek }\end{array}$} & Médico/Professor \\
\hline $\begin{array}{l}\text { Celso Brant } \\
\text { (interino) }\end{array}$ & $30 / 04 / 1956$ & 2/10/1956 & & Advogado/Professor \\
\hline $\begin{array}{l}\text { Nereu Ramos } \\
\text { (interino) }\end{array}$ & $3 / 10 / 1956$ & $4 / 11 / 1956$ & & Advogado \\
\hline $\begin{array}{c}\text { Clóvis Salgado da } \\
\text { Gama }\end{array}$ & $4 / 11 / 1956$ & $18 / 06 / 1959$ & & Médico/Professor \\
\hline Pedro Calmon & $18 / 06 / 1959$ & $16 / 061960$ & & Advogado/Professor \\
\hline $\begin{array}{l}\text { José Pedro Ferreira } \\
\text { da Costa (interino) }\end{array}$ & $17 / 06 / 1960$ & $24 / 06 / 1960$ & & Político \\
\hline Pedro Paulo Penido & $1 / 07 / 1960$ & $17 / 10 / 1960$ & & Dentista/ Político \\
\hline $\begin{array}{c}\text { Clóvis Salgado da } \\
\text { Gama }\end{array}$ & $18 / 10 / 1960$ & $31 / 01 / 1961$ & & Médico/Professor \\
\hline $\begin{array}{c}\text { Brígido Fernandes } \\
\text { Tinoco }\end{array}$ & 31/01/1961 & 25/08/1961 & Jânio Quadros & Advogado/Político \\
\hline $\begin{array}{l}\text { Antônio Ferreira de } \\
\text { Oliveira Brito }\end{array}$ & $8 / 09 / 1961$ & $11 / 07 / 1962$ & \multirow{3}{*}{$\begin{array}{c}\text { João Goulart } \\
\text { parlamentarismo }\end{array}$} & Advogado \\
\hline Roberto Lira & $12 / 07 / 1962$ & $14 / 09 / 1962$ & & Advogado \\
\hline Darcy Ribeiro & $18 / 09 / 1962$ & 23/01/1963 & & Antropólogo \\
\hline $\begin{array}{c}\text { Teotônio Monteiro } \\
\text { de Barros }\end{array}$ & 23/01/1963 & $18 / 06 / 1963$ & \multirow{2}{*}{$\begin{array}{c}\text { João Goulart } \\
\text { presidencialismo }\end{array}$} & Advogado \\
\hline $\begin{array}{l}\text { Paulo de Tarso } \\
\text { Santos }\end{array}$ & $18 / 06 / 1963$ & $21 / 10 / 1963$ & & Advogado \\
\hline
\end{tabular}




\begin{tabular}{|c|c|c|c|c|}
\hline $\begin{array}{c}\text { Júlio Furquim } \\
\text { Sambaqui (interino) }\end{array}$ & $21 / 10 / 1963$ & $6 / 04 / 1964$ & & Contabilista \\
\hline
\end{tabular}

Fonte: Galeria de Ministros (www.gov.br/mec/pt-br/acesso-a-informacao/institucional/galeriade-ministros?b_start:int=40). Acesso em 26, jan. 2021

A quantidade de Ministros que atuaram neste período evidenciou que a permanência no cargo de comando do Ministério da Educação era breve. Juscelino Kubitschek (1956 a 1961) ficou no governo por cinco anos e nomeou seis Ministros, embora dois fossem interinos, na sequência, vem João Goulart que em cerca de um ano e oito meses na presidência nomeou seis ministros, sendo um interino. Em um período de quatro anos e meio, Gaspar Dutra nomeou quatro Ministros, um interino.

Nenhum dos presidentes deste período indicou uma mulher para atuar na gestão da educação brasileira. A maior parte dos ministros tinham por formação primeira a advocacia, seguido de medicina, antropologia, contabilidade, um político (em sua biografia não consta formação). Visitando a biografia dos Ministros, apenas um Ministro, Abgar Renault, tinha a formação de professor. Sua escolarização deu-se toda em Belo Horizonte onde começou a exercer o magistério. Trabalhou como professor no Ginásio Mineiro de Belo Horizonte e na Universidade Federal de Minas Gerais. Mudou-se posteriormente para o Rio de Janeiro onde ministrou aulas no Colégio Pedro II e na Universidade do Distrito Federal. Sua passagem pelo Ministério foi de pouco mais de dois meses, de 24 de novembro de 1955 a 31 de janeiro de 1956. Na biografia de cinco Ministros a função de professor aparece de forma complementar.

Este período da história educacional brasileira é considerado de grande efervescência, com muitas mudanças que influenciaram a condução das políticas educacionais. A Constituição de 1946 trouxe avanços, entre elas a clareza em relação à competência da União, "legislar sobre as diretrizes e bases da educação nacional" (Art. 50, XV). A figura do Ministro da Educação ganha expressão e importância e sua atuação é determinante na condução das políticas nacionais para a educação brasileira. De acordo com Vieira e Farias (2011) a expressão “ensino oficial” irá surgir pela primeira vez em uma Constituição. Independente da tensão entre publicistas e privatistas que perdura no período, a educação pública avança e compete ao Ministério da Educação conduzir as políticas que garantam educação pública, laica e gratuita.

A primeira Lei de Diretrizes e Bases da Educação Nacional traz para o debate nacional as principais questões de âmbito social, político, educacional e pedagógico. Foi um longo percurso até a sua aprovação no Congresso Nacional, ou seja, em 1948 tem 
início a discussão de forma ampliada, mas só em 1961 a primeira LDBEN é promulgada. Entretanto, na visão de Saviani (1997, p. 6), "passados 13 anos, a lei aprovada em 20 de dezembro de 1961 não correspondeu àquela expectativa".

Os Ministros da Educação que conduziram e acompanharam o processo de discussão da primeira LDBEN brasileira não tinham, em boa medida, a experiência única na docência, tampouco na educação básica. Em sua maior parte, foram advogados, médicos e políticos que estiveram à frente do debate. João Goulart, presidente do Brasil à época sanciona a LDBEN 4.024/61, juntamente com $14^{5}$ políticos, todos homens.

\section{DITADURA MILITAR: 1964-1985}

Nos vinte anos que seguem o Brasil será conduzido por militares. O golpe de 1964 trouxe o fechamento da ordem política. Na educação, o regime traduz "uma clara inflexão na política existente. Sob a égide da ditadura, novos instrumentos legais orientam o País" (VIEIRA E FARIA, 2011, p.146-147).

O Brasil esteve sob o comando de cinco presidentes e um período curto da Junta Governativa Provisória de 1969. Para o Ministério da Educação e Cultura foram nomeados 13 Ministros, entre eles a primeira mulher, Esther de Figueiredo Ferraz no governo de João Figueiredo. O Quadro 3, a seguir, traz os nomeados.

Quadro 3: Ministros da Educação, Cultura e Desporto - Brasil -1964- 1985

\begin{tabular}{|c|c|c|c|c|}
\hline Nome & Início & Fim & Presidente & Formação \\
\hline $\begin{array}{l}\text { Luís Antônio da } \\
\text { Gama e Silva }\end{array}$ & 6/04/1964 & $15 / 04 / 1964$ & $\begin{array}{l}\text { Ranieri } \\
\text { Mazzilli }\end{array}$ & Advogado \\
\hline \multirow{2}{*}{$\begin{array}{l}\text { Flávio Suplicy } \\
\text { de Lacerda }\end{array}$} & $15 / 04 / 1964$ & $08 / 03 / 1965$ & \multirow{4}{*}{$\begin{array}{l}\text { Castelo } \\
\text { Branco }\end{array}$} & \multirow{2}{*}{ Engenheiro/Professor } \\
\hline & $22 / 04 / 1965$ & $10 / 01 / 1966$ & & \\
\hline Pedro Aleixo & $10 / 01 / 1966$ & $30 / 06 / 1966$ & & Advogado/Jornalista \\
\hline $\begin{array}{c}\text { Raymundo } \\
\text { Augusto de } \\
\text { Castro Moniz de } \\
\text { Aragão }\end{array}$ & $30 / 06 / 1966$ & $04 / 10 / 1966$ & & Médico/Professor \\
\hline
\end{tabular}

5 Assinam a LDB 4.024/61 juntamente com João Goulart: Tancredo Neves Alfredo Nasser Angelo Nolasco João de Cegadas Viana San Tiago Dantas Walther Moreira Salles Vigílio Távora Armando Monteiro Antonio de Oliveira Brito A. Franco Montouro Clovis M. Travassos Souto Maior Ulysses Guimarães Gabriel de R. Passos. 


\begin{tabular}{|c|c|c|c|c|}
\hline $\begin{array}{c}\text { Guilherme } \\
\text { Augusto Canedo } \\
\text { de Magalhães }\end{array}$ & $\begin{array}{l}04 / 10 / 1966 \\
21 / 10 / 1966\end{array}$ & $\begin{array}{l}17 / 10 / 1966 \\
10 / 11 / 1966\end{array}$ & & Político \\
\hline Tarso Dutra & $15 / 03 / 1967$ & $05 / 12 / 1967$ & \multirow{2}{*}{ Costa e Silva } & Advogado/Político \\
\hline $\begin{array}{c}\text { Favorino Bastos } \\
\text { Mércio }\end{array}$ & $13 / 12 / 1967$ & $31 / 08 / 1969$ & & Advogado/Político \\
\hline $\begin{array}{c}\text { Favorino Bastos } \\
\text { Mércio }\end{array}$ & $31 / 08 / 1969$ & 03/11/1969 & $\begin{array}{c}\text { Junta } \\
\text { Governativa } \\
\text { Provisória de } \\
1969\end{array}$ & Advogado/Político \\
\hline $\begin{array}{c}\text { Jarbas } \\
\text { Passarinho }\end{array}$ & $03 / 11 / 1969$ & $15 / 03 / 1974$ & $\begin{array}{l}\text { Emílio G. } \\
\text { Médici }\end{array}$ & Militar/Político \\
\hline Ney Braga & $15 / 03 / 1974$ & $30 / 05 / 1978$ & \multirow[b]{2}{*}{$\begin{array}{c}\text { Ernesto } \\
\text { Geisel }\end{array}$} & Militar/Político \\
\hline Euro Brandão & $30 / 05 / 1978$ & $14 / 03 / 1979$ & & Engenheiro/Filósofo/Professor \\
\hline Eduardo Portella & $15 / 03 / 1979$ & $22 / 11 / 1980$ & \multirow{3}{*}{$\begin{array}{c}\text { João } \\
\text { Figueiredo }\end{array}$} & Professor/Escritor/ \\
\hline $\begin{array}{c}\text { Rubem Carlos } \\
\text { Ludwig }\end{array}$ & $27 / 11 / 1980$ & $24 / 08 / 1982$ & & Militar \\
\hline $\begin{array}{l}\text { Esther de } \\
\text { Figueiredo } \\
\text { Ferraz }\end{array}$ & $24 / 08 / 1982$ & $15 / 03 / 1985$ & & Advogada/Professora \\
\hline
\end{tabular}

Fonte: Galeria de Ministros

(www.gov.br/mec/pt-br/acesso-a-informacao/institucional/galeriade-ministros?b_start:int=40). Acesso em 26, jan. 2021.

Mais uma vez a formação em Direito ganha destaque entre os escolhidos, entretanto o registro de militares à frente da pasta pode ser observado, o que condiz com a política governamental após o golpe na democracia brasileira.

Diferente dos presidentes anteriores, a permanência dos ministros nos cargos é maior. Emílio G. Médici, por exemplo, teve praticamente um ministro em todo o seu período presidencial, o militar Jarbas Passarinho. João Figueiredo permaneceu no governo seis anos e nomeou três ministros. Foi em seu governo que o Ministério teve à frente na condução das políticas públicas educacionais a primeira mulher, Esther de Figueiredo Ferraz. Antes de se formar advogada, em 1944, lecionou na Escola Normal Caetano de Campos entre os anos de 1939 e 1943. Foi a primeira mulher a lecionar na Universidade de São Paulo e a primeira mulher na América Latina a comandar a reitoria de uma universidade, a Mackenzie. Em seu discurso de posse no Ministério, Esther defende a presença das mulheres em cargos de comando e faz referência aos proletariados: 
[...] Finalmente, fizeram as circunstâncias que eu fosse a primeira mulher a ocupar, em nossa terra, o cargo de ministro de Estado, e houve por bem o sr. Presidente, da República conduzir-me à Pasta onde mais utilizáveis parecem tornar-se, em termos de interesse coletivo, os dotes femininos, aqueles dotes intelectuais, de caráter e de sensibilidade que traduzem verdadeiras inclinações ou tropismos de alma, e que tornam toda mulher - seja ela quem for, grande dama ou humilde proletária - uma educadora. As operárias, as camponesas, as comerciárias, as funcionárias públicas, as profissionais liberais, as estudantes de todos os graus do ensino e, de maneira muito especial, as integrantes da mais forte das milícias desarmadas que é o exército das "prendas domésticas", das valorosas donas-de-casa e mães de família, todas elas tomam parte, ainda que à distância, no ato público que ora se está realizando. Cada uma delas percebe, dado o alto simbolismo de que se reveste a cerimônia, em si mesma representativa de um grande gesto de abertura, que hoje e aqui está acontecendo algo que toca muito de perto a sorte do feminismo brasileiro, tomado este em seu sentido sadio e construtivo. (Site Mulher 500 anos atrás dos panos - www.mulher500.org.br/biografia-de-mulheres. Acesso em 26.01.2021)

Chama-nos a atenção a formação do Ministro Euro Bandão, nomeado por Ernesto Geisel, que ficou frente ao Ministério quase um ano. Era engenheiro, professor, filósofo, escritor brasileiro, membro da Academia Paranaense de Letras. No período em que esteve no MEC "buscou implementar um programa nacional para a pré-escola, além da instalação de projetos-pilotos para melhorar a educação rural no Nordeste do Brasil" (Galeria de Ministros MEC).

Eduardo Portella, foi Ministro de Estado da Educação, Cultura e Desportos também no governo João Figueiredo, de 15 de março de 1979 a 26 de novembro de 1980, lutando pela anistia. Consta em sua biografia a seguinte fala: "O que me deixou contente foi ter sido convidado a ser ministro da Abertura. Nem sempre os meus prazos coincidiram com os dos militares, sobretudo da comunidade de informações. Mas eu, como ministro, recusei a censura, anistiei todos" (MEC/Galeria de Ministros). Quando apoiou a greve dos professores da Universidade Federal Rural do Rio de Janeiro, apresentou sua demissão ao governo. Entre os registros de suas falas, ficou marcada a expressão: "Não sou ministro; estou ministro", demonstrando a transitoriedade dos cargos públicos.

\section{DE VOLTA À DEMOCRACIA}

Os anos 1985 abrem as portas para mudanças. Retorno do Estado Democrático de Direito, abertura política, participação popular, nova Constituição Federal. Conforme Cury (2002, p. 172), “[...] o Estado de Direito é um Estado em que se tem a soberania da lei, a legitimidade do sistema representativo baseado no voto popular e nas regras do jogo e a defesa dos direitos subjetivos contra o poder arbitrário.” Em 1988, os brasileiros e 
brasileiras vêm no dia 05 de outubro a promulgação da Constituição Cidadã, portanto, institui-se a regulação da democratização do e pelo próprio Estado.

As mudanças não vêm a galope e o país vai vivenciar um momento difuso, em um processo de construção tendo por pano de fundo as influências neoliberais na economia, nas políticas sociais incluindo a educação. Teixeira (1977, p. 206) nos põe a refletir quando afirma: “A democracia é, pois, todo um programa evolutivo de vida humana [...] ainda não conseguiu de todo vencer sequer a fase de controvérsia e negação, por que passa toda transformação histórica." E o autor continua: "O postulado da democracia, acentuo, liga o programa de vida que representa a um programa de educação, sem o qual, uma organização democrática não poderia sequer ser sonhada.” (TEIXEIRA, 1977, P. 206). Nesse sentido, compreendemos a relação intrínseca entre educação e democracia ou, em um sentido que denota finalidade, a educação para a democracia, também afirmado por Paro (2007, p. 23).

Como bem dizem Viera e Farias (2011, p. 172):

O retorno à democracia no Brasil, não se dá por simples outorga ou concessão dos militares. Como já observado, trata-se de conquista lenta, forjada no território dos movimentos sociais, iniciados desde o final da década de 70, com as greves dos metalúrgicos do ABC paulista (1978) e outras lutas políticas pelo direito a uma cidadania plena.

Um período de grandes conquistas para a educação, com destaque para a aprovação da LDBEN 9.394/1996, dois Planos Nacionais de Educação (2001-2010) e (2014-2024), aprovação do FUNDEF (1998-2006) (Fundo de Manutenção e Desenvolvimento do Ensino Fundamental e de Valorização do Magistério) e FUNDEB (2007 - atual) (Fundo de Manutenção e Desenvolvimento da Educação Básica e de Valorização dos Profissionais da Educação), aprovação do Piso Nacional para os Profissionais da Educação, Lei $n^{\circ} 11.738$, de 16 de julho de 2008, expansão da Rede Federal de Ensino, e políticas públicas de acesso e permanência no ensino superior. Todas estas conquistas ainda que sob constantes ameaças nos últimos dois anos, foram frutos de amplo debate e tensão permanente no Congresso Nacional e na sociedade por meio dos movimentos sociais.

Tivemos, nestes trinta e cinco anos, oito presidentes, e o primeiro eleito após a ditadura militar: Fernando Collor de Melo (1990 - 1992). Neste período, foi criado o Ministério da Cultura em 1985, retirando as atribuições deste campo do Ministério da Educação. Em 1992, uma lei federal transformou o MEC no Ministério da Educação e do 
Desporto. Somente em 1995 a instituição passou a ser responsável apenas pela área da educação, porém permanece a sigla MEC.

Neste mesmo período, ou seja, de 1985 aos dias atuais, o Ministério da Educação contou com vinte e dois ministros. Um fato atípico ocorreu em 2020, quando em 25 de junho foi nomeado para o cargo de Ministro da Educação Carlos Decotelli, no entanto não chegou a tomar posse e, por esta razão, sua nomeação foi tornada sem efeito. O cargo de Ministro fica vago por quase 01 mês e o Ministério à deriva. Também não houve nestes trinta e cinco anos a nomeação de mulher para o cargo. A história brasileira registra apenas uma mulher Ministra da Educação, conforme trouxemos no item anterior.

O Quadro 4, a seguir, traz as informações dos Ministros da Educação no período.

Quadro 4: Ministros da Educação - Brasil -1985 a 2020

\begin{tabular}{|c|c|c|c|c|}
\hline Nome & Início & Fim & Presidente & Formação \\
\hline Marco Maciel & $15 / 03 / 1985$ & $14 / 02 / 1986$ & \multirow{5}{*}{ José Sarney } & Advogado/Professor \\
\hline $\begin{array}{c}\text { Jorge } \\
\text { Bornhausen }\end{array}$ & $14 / 02 / 1986$ & $5 / 10 / 1987$ & & Advogado \\
\hline $\begin{array}{c}\text { Aloísio } \\
\text { Guimarães } \\
\text { Sotero (interino) }\end{array}$ & $6 / 10 / 1987$ & $30 / 10 / 1987$ & & Político \\
\hline $\begin{array}{l}\text { Hugo Napoleão } \\
\text { do Rego Neto }\end{array}$ & 3/11/1987 & $16 / 01 / 1989$ & & Advogado \\
\hline $\begin{array}{c}\text { Carlos Corrêa de } \\
\text { Menezes } \\
\text { Sant'anna }\end{array}$ & $16 / 01 / 1989$ & $14 / 03 / 1990$ & & Médico/Professor \\
\hline Carlos Chiarelli & $15 / 03 / 1990$ & $21 / 08 / 1991$ & \multirow{3}{*}{$\begin{array}{l}\text { Fernando } \\
\text { Collor }\end{array}$} & Advogado/Professor \\
\hline José Goldemberg & $22 / 08 / 1991$ & 4/08/1992 & & Físico/Professor \\
\hline Eraldo Tinoco & 4/08/1992 & $1 / 10 / 1992$ & & Administrador \\
\hline $\begin{array}{c}\text { Murílio de } \\
\text { Avellar Hingel }\end{array}$ & 1/10/1992 & $1 / 01 / 1995$ & $\begin{array}{l}\text { Itamar } \\
\text { Franco }\end{array}$ & Professor \\
\hline $\begin{array}{l}\text { Paulo Renato } \\
\text { Souza }\end{array}$ & $1 / 01 / 1995$ & $1 / 01 / 2003$ & $\begin{array}{c}\text { Fernando } \\
\text { Henrique } \\
\text { Cardoso }\end{array}$ & Economista \\
\hline $\begin{array}{l}\text { Cristovam } \\
\text { Buarque }\end{array}$ & $1 / 01 / 2003$ & $27 / 01 / 2004$ & \multirow{3}{*}{$\begin{array}{l}\text { Luiz Inácio } \\
\text { Lula da } \\
\text { Silva }\end{array}$} & $\begin{array}{c}\text { Engenheiro/ } \\
\text { Economista/Professor }\end{array}$ \\
\hline Tarso Genro & $27 / 01 / 2004$ & $29 / 07 / 2005$ & & Advogado/Jornalista \\
\hline $\begin{array}{c}\text { Fernando } \\
\text { Haddad }\end{array}$ & $29 / 07 / 2005$ & $1 / 01 / 2011$ & & Advogado/Professor \\
\hline Fernando Haddad & $1 / 01 / 2011$ & $23 / 01 / 2012$ & & Advogado/Professor \\
\hline
\end{tabular}




\begin{tabular}{|c|c|c|c|c|}
\hline $\begin{array}{c}\text { Aloizio } \\
\text { Mercadante }\end{array}$ & $24 / 01 / 2012$ & 2/02/2014 & \multirow[t]{6}{*}{$\begin{array}{c}\text { Dilma } \\
\text { Rousseff }\end{array}$} & Economista \\
\hline $\begin{array}{c}\text { José Henrique } \\
\text { Paim }\end{array}$ & $3 / 02 / 2014$ & $1 / 01 / 2015$ & & Economista /Professor \\
\hline Cid Gomes & $1 / 01 / 2015$ & $18 / 03 / 2015$ & & Engenheiro \\
\hline $\begin{array}{c}\text { Luiz Cláudio } \\
\text { Costa (interino) }\end{array}$ & $18 / 03 / 2015$ & $6 / 04 / 2015$ & & Engenheiro/Professor \\
\hline $\begin{array}{l}\text { Renato Janine } \\
\text { Ribeiro }\end{array}$ & $6 / 04 / 2015$ & $1 / 10 / 2015$ & & Professor \\
\hline $\begin{array}{c}\text { Aloizio } \\
\text { Mercadante }\end{array}$ & $2 / 10 / 2015$ & $12 / 05 / 2016$ & & Economista \\
\hline Mendonça Filho & $12 / 05 / 2016$ & $6 / 04 / 2018$ & \multirow{2}{*}{$\begin{array}{l}\text { Michel } \\
\text { Temer }\end{array}$} & Administrador \\
\hline Rossieli Soares & $6 / 04 / 2018$ & $31 / 12 / 2018$ & & Advogado \\
\hline $\begin{array}{c}\text { Ricardo Vélez } \\
\text { Rodríguez }\end{array}$ & $1 / 01 / 2019$ & $8 / 04 / 2019$ & \multirow{4}{*}{$\begin{array}{c}\text { Jair Messias } \\
\text { Bolsonaro }\end{array}$} & Filósofo/Professor \\
\hline $\begin{array}{c}\text { Abraham } \\
\text { Weintraub }\end{array}$ & $9 / 04 / 2019$ & $19 / 06 / 2020$ & & Economista/Professor \\
\hline vago & $\begin{array}{l}20 \text { de junho } \\
\text { de } 2020\end{array}$ & $\begin{array}{l}16 \text { de julho } \\
\text { de } 2020\end{array}$ & & - \\
\hline Milton Ribeiro & $16 / 07 / 2020$ & atual & & Advogado/Professor \\
\hline
\end{tabular}

Fonte: Galeria de Ministros (www.gov.br/mec/pt-br/acesso-a-informacao/institucional/galeriade-ministros?b_start:int=40). Acesso em 26, jan. 2021

A relação demonstrada no Quadro 4 evidencia que foram Fernando Henrique Cardoso (FHC) (1995 - 2003) e Itamar Franco (1992 - 1995) os presidentes que nomearam apenas um ministro em todo o seu mandato, como foi o de Itamar Franco, um governo curto com cerca de três anos, ou longo, de oito anos, caso de FHC. Luiz Inácio Lula da Silva (2003 - 2010) ocupou a presidência do Brasil por dois mandatos e nomeou três Ministros, dando a Fernando Haddad seis anos de permanência no Ministério em seu governo. Considerando-se o tempo de permanência na função, o advogado e professor Haddad foi o segundo Ministro, com sete anos ao todo, sendo seis no governo Lula e um ano no governo da presidenta Dilma Rousseff (2011 - 2016), ficando atrás apenas de Paulo Renato Souza, (economista), que foi Ministro por oito anos no governo FHC. Os demais presidentes e a presidenta realizaram várias trocas de seus Ministros da Educação, com destaque para Jair Messias Bolsonaro (2019 - atual) que em dois anos nomeou quatro ministros, considerando a curtíssima passagem de Carlos Decotelli que foi nomeado, porém não empossado. 
A formação dos Ministros da Educação após a retomada da democracia brasileira não foi muito diferente dos demais, os advogados ganham destaque na função, seguidos de economistas, administradores e engenheiros. Contudo, alguns deles exerceram a função de professores universitários, a exceção fica com três ministros: o Ministro Murílio de Avellar Hingel, graduado em Geografia e História pela Faculdade de Filosofia e Letras (FAFILE) da Universidade Federal de Juiz de Fora; Renato Janine Ribeiro, professor-titular da cadeira de Ética e Filosofia política da Faculdade de Filosofia, Letras e Ciências Humanas da Universidade de São Paulo (FFLCH-USP) e Ricardo Vélez Rodríguez que se licenciou em Filosofia pela Pontifícia Universidade Javeriana (Bogotá), em 1963. Grande parte dos Ministros atuaram na educação superior em cargos de gestão, como reitorias, mas não tiveram na formação primeira em nível superior cursos de licenciatura.

\section{A EVIDÊNCIA DA DESCONTINUIDADE NAS POLÍTICAS EDUCACIONAIS E A FORMAÇÃO PEDAGÓGICA}

Os números levantados neste estudo nos impelem a discutir algumas questões relacionadas às políticas para a educação no Brasil nestes setenta anos.

Em um período da nossa história que experenciamos golpes civis e militares, abertura e cerceamento da liberdade política, crescimento desordenado da economia, recessão econômica, retomada do processo democrático, entre outros avanços e retrocessos os quais sofreram e ainda sofrem grandes influências externas de diferentes mecanismos econômicos internacionais, a educação teve setenta e um Ministros da Educação. De forma geral pode-se dizer que tivemos um ministro a cada ano civil. Esta troca de gestores, na maior parte destes anos, desvelou que o princípio da continuidade não foi uma preocupação no plano de gestão dos governos presidenciais.

A falta de planejamento e continuidade são fragilidades das e nas políticas de qualquer setor, contribuindo para o insucesso das políticas públicas. Já em 1932, no Manifesto dos Pioneiros da Escola Nova, registra-se:

No plano de reconstrução educacional, de que se esboçam aqui apenas as suas grandes linhas gerais, procuramos, antes de tudo, corrigir o erro capital que apresenta o atual sistema (se é que se pode chamar sistema), caracterizado pela falta de continuidade e articulação do ensino, em seus diversos graus, como se não fossem etapas de um mesmo processo, e cada um dos quais deve ter o seu "fim particular", próprio, dentro da "unidade do fim geral da educação" e dos princípios e métodos comuns a todos os graus e instituições educativas. (HISTEDBR, p. 196-197, grifo nosso). 
As políticas públicas no Brasil estão sustentadas em um modelo de Estado democrático, mas o que vigora como sistema político é o da democracia representativa. Nesse sentido, a tomada de decisão passa pelo povo de forma indireta, uma vez que ao eleger determinado candidato, seja por força do voto direto ou pelo voto de legenda, o eleitor delega as decisões ao eleito, não mais sendo consultado.

As políticas públicas emanadas pelo Estado traduzem seus interesses, ideologias, sua compreensão de sociedade e evidenciam as bases nas quais a gestão se consolida. Azevedo (2003, p. 38), ao tratar do tema, definiu que "[...] política pública é tudo o que um governo faz e deixa de fazer, com todos os impactos de suas ações e de suas omissões”. São, portanto, construções sociais e históricas. Nos dizeres de Gomes (2011, p.20): “Toda política pública é fundamentalmente uma forma de preservação ou de redistribuição do quantum de poder social que circula, alimenta e engendra as forças vivas da sociedade". Esta relação é conflituosa e complexa, depende de alianças de classes e grupos sociais, e precisamente da configuração do Estado. Ora, a gestão educacional enquanto ação política na sua superestrutura, reverbera nas demais instâncias até chegar à gestão da escola, concepções que convergem ou não com o modelo de sociedade e de homem que se deseja formar.

Não iremos aqui aprofundar sobre os modelos de gestão assumidos pelos governos no Brasil neste período, intentamos apenas ressaltar que independente do modelo de gestão que estruturou e direcionou as políticas educacionais brasileiras, questões como continuidade de um planejamento para o país de forma articulada, a formação pedagógica dos dirigentes da educação no nível macro estiveram ausentes do debate em nível nacional.

Ao tratar sobre governança e os mecanismos de gestão que lhe possibilitam efetividade, Dowbor (2014, p. 103 - 104) nos mostra a relevância do planejamento:

Um segundo instrumento público de gestão fundamental é o planejamento. É particularmente importante, como vimos, nas infraestruturas, que precisam de uma visão sistêmica e de longo prazo, mas também na construção de visões de longo prazo em termos de política tecnológica, de inserção e articulação com o subcontinente, de escolha de áreas chave de desenvolvimento dadas as vocações naturais ou geoeconômicas do país e assim por diante.

$[\ldots]$

A ausência gritante de planejamento nos mostra por exemplo os custos sociais nas grandes cidades, onde todos pagamos por políticas decididas no varejo, segundo quem quer faturar com um viaduto ou uma canalização de córrego (grifo nosso). 
O sucesso de todo planejamento, independente da área, está na sequência de suas ações. Há que se considerar que os resultados não ocorrem em consonância com o tempo de permanência deste ou daquele gestor em seus cargos. As políticas públicas guardam estreita relação entre Estado e sociedade e dependem da distinção entre política de estado e de governo. Bordignon (2014, p. 37-38) define que políticas de estado podem ser identificadas a partir de três dimensões básicas: a dimensão do processo de construção coletiva, de ampla participação social e traduz as aspirações da sociedade; a dimensão legal quando a política ganha legalidade com aprovação em instância legislativa e se torna mandatária da ação do governo; e a dimensão temporal, quando ultrapassa os tempos de governos. O que se tem evidenciado nos últimos anos são programas de governo que tentam minimizar questões pontuais em relação à educação, como evasão, repetência, diretrizes curriculares, entre outros, mas que se circunscrevem ao campo das políticas de governo, não sendo políticas públicas que ultrapassam os mandatos eletivos. A cada eleição, considerando os períodos em que escolhemos nossos representantes, principalmente quando ocorre alternância de partidos, grande parte das políticas públicas fomentadas pela gestão que deixa o poder é abandonada pela nova gestão, uma vez que não constitui uma política pública de estado, uma política de nação.

Além da interrupção dos planejamentos, os quais foram substituídos ou alterados por novos programas, à medida que a alternância de Ministros se efetivou no Brasil, este estudo mostrou que dos setenta e dois Ministros da Educação, vinte e cinco (menos de $35 \%$ ) eram professores, sendo que três licenciados, o que representa $4 \%$ e apenas um Ministro foi professor da Educação Básica. Neste aspecto, há que se reforçar a inobservância da formação pedagógica destes gestores por parte do executivo nacional, no momento da escolha. Outros fatores foram imperativos para a nomeação, porém em nossa análise a ausência desta formação colocou a discussão das Diretrizes e Bases da Educação Nacional nas mãos de pessoas que não possuíam formação intelectual do campo para conduzir o destino educacional do Brasil. Por certo, não se faz uma gestão nacional de forma isolada e solitária. Há que ser considerado que um bom gestor cercase de intelectuais capazes e referenciados por seus pares para a elaboração de projetos e planos, contudo, a presença de autoridades intelectuais do campo dá às discussões e enfrentamentos nas disputas políticas, mais segurança, transparência e representatividade. Neste último caso a representatividade do campo docente, tão importante no debate da educação básica e superior por entendê-las por dentro, por meio de suas próprias experiências. 
A ausência de mulheres no principal cargo de gestão da educação brasileira demonstra que o caminho para a superação das questões de gênero no Brasil ainda é longo, complexo e denota uma posição dos governos que assumem a gestão do Estado, contrária à competência gestora das mulheres.

O magistério foi historicamente a profissão indicada e apropriada para mulheres. Afonso, Mesquita e Carneiro (2018, p. 28) apresentam a contradição desta participação das mulheres na educação pois, embora o magistério dado "[...] à valorização das qualidades e habilidades femininas, evidentemente construções ideológicas de naturalização, validando o magistério como uma profissão feminilizada", a presença da mulher em espaço político e em diferentes funções, a exemplo da gestão, ainda se apresenta como um desafio a ser superado. De acordo com estudo realizado pelas autoras, em 2010, as mulheres na Câmara Federal representavam 8,8\% dos 513 deputados. Em 2014 este número apresentou um discreto aumento e no ano de 2018 a bancada feminina contou com 51 deputadas (9,95\% das 513 cadeiras) e 13 senadoras (16\% das 81 vagas).

Este cenário de ausência feminina expressa que para cargos de gestão em nível federal, como o de Ministro da Educação, a mulher não foi e não é uma opção considerada nestes 70 anos, exceção constatada no período de 24/08/1982 a 15/03/1985, ou seja, pouco mais de dois anos.

As evidências trazidas no presente estudo nos permitem algumas considerações as quais trazemos na última seção do texto.

\section{CONSIDERAÇÕES FINAIS}

Para responder à questão elaborada no início do presente artigo: qual a formação inicial dos Ministros da Educação do Brasil e a formação em cursos de licenciatura aparece como indicativo nas escolhas destas pessoas para o cargo principal da educação no Brasil e, por fim, como se dá presença da mulher no mesmo período, construímos um caminho a partir dos períodos históricos.

Organizamos quadros ilustrativos com algumas informações obtidas por meio da Galeria de Ministros no site do Ministério da Educação, que dispõe relação tanto dos presidentes do Brasil desde a Proclamação da República até os dias atuais como de seus Ministros. O recorte para este artigo foi o período compreendido entre os anos 1930 a 2020.

Confirmamos que, apesar de termos vivenciados momentos de efervescente discussão democrática, ditadura civil e militar, e redemocratização do sistema político do 
país, o cargo de Ministro da Educação foi ocupado uma única vez por uma mulher: Esther de Figueiredo Ferraz, de 24/08/1982 a 15/03/1985, no período militar.

A formação dos Ministros e da Ministra revelou que o fato de terem como formação primeira cursos de licenciatura, ou seja, aqueles que de fato preparam os profissionais para a docência e para a compreensão do fenômeno da educação em diferentes níveis e etapas, não se apresentou como indicativo precípuo para a escolha dos nomes. A maior parte dos Ministros teve como formação o curso de bacharel em Direito, bem como em outras áreas como Medicina, Economia, Administração, Engenharia. Poucos foram os que receberam a formação em licenciatura exclusivamente.

Outra indicação que o estudo revelou foi a pouca permanência dos Ministros nos cargos, com raras exceções, caso dos Ministros Paulo Renato Souza e Fernando Haddad, o primeiro permaneceu os oito anos da gestão de FHC e o segundo permaneceu sete anos, sendo que seis anos no governo Lula e um ano no governo Dilma, quando fez a transição de governos.

O estudo não nos permite afirmar que as crises pelas quais a educação nacional vem atravessando, desde a criação do Ministério da Educação e Saúde em 1930, está relacionada à pouca longevidade dos Ministros em seus cargos, porém este fato nos chama a atenção, uma vez que a permanência de pessoas em seus cargos fortalece o princípio da continuidade, o que significa dizer que os serviços públicos devem ser prestados de maneira contínua, com sistematização de um planejamento ancorado em concepções de sociedade e educação. Princípio descumprido no governo de Jair Messias Bolsonaro, quando deixou o MEC à deriva entre 20 de junho de 2020 a 16 de julho de 2020.

Embora seja fato que a presença das mulheres no mundo do trabalho é crescente, e que sua contribuição no rendimento familiar associada à elevação da escolaridade feminina são aspectos que nos levam a inferir que sua presença na sociedade vem sendo redimensionada. A ausência de mulheres no principal cargo de comando da educação brasileira ainda é um desafio a ser superado.

\section{REFERÊNCIAS BIBLIOGRÁFICAS}

AFONSO, L. H. R; MESQUITA, M. C. D.; CARNEIRO, M. E. F. Políticas Públicas Pós- Constituição Federal de 1988: reflexões com recorte de gênero. In: CARVALHO, C. E. C. et al (org.) 30 anos da Constituição Federal Brasileira: conquistas e desafios para a construção de um Estado Democrático de Direito. Goiânia: Kelps, 2018. p. 23-47. 
AZEVEDO, J. M. L. A educação como política pública. Campinas: Autores Associados, 2003.

BIOGRAFIA DE MULHERES. Mulher 500 anos atrás dos panos - Disponível em: www.mulher500.org.br/biografia-de-mulheres. Acesso em 26, jan. 2021

BORDIGNON, G. Caminhar da educação brasileira: muitos planos, pouco planejamento IN: SOUZA, Donaldo Bello de; MARTINS, Angela Maria (org). Planos de Educação no Brasil: Planejamento, Políticas e Práticas. São Paulo: Edições Loyola, 2014.

BRASIL. Decreto n. ${ }^{\circ}$ 19.402, de 14 de novembro de 1930. Disponível em: https://www2.camara.leg.br/legin/fed/decret/1930-1939/decreto-19402-14-novembro1930-515729-publicacaooriginal-1-pe.html Acesso em 14 de dez de 2020.

BRASIL. Galeria de Ministros site do MEC (www.gov.br/mec/pt-br/acesso-ainformacao/institucional/galeria-de-ministros?b_start:int=40). Acesso em 26, jan. 2020.

BRASIL. Constituição dos Estados Unidos do Brasil de 18 de setembro de 1946. Disponível em:

https:http://www.planalto.gov.br/ccivil_03/Constituicao/Constituicao46.htm. Acesso em 15 de dez 2020.

BRASIL.MEC. Portal. Disponível em: https://www.gov.br/mec/pt-br/acesso ainformacao/institucional/competencias). Acesso em 27, jan. 2020

CURY, C. R. J. Gestão Democrática da Educação: exigências e desafios. RBPAE, v. 18, n.02, jul/dez. 2002.

DOWBOR, L. Os estranhos caminhos do nosso dinheiro. Editora Fundação Perseu Abramo, São Paulo, 2014.

GOMES, A. M. (org.) Políticas Públicas e Gestão da Educação. Campinas/SP:

Mercado de Letras, 2011. Série Estudos em Políticas Públicas e Educação.

PARO, V. H. Gestão escolar, democracia e qualidade do ensino. São Paulo: Ática, 2006.

SAVIANI, D. A Nova Lei da Educação - Trajetórias Limites e Perspectivas. Campinas: Editora Autores Associados, 1997.

TEIXEIRA. A. Democracia e educação In: Educação e o mundo moderno, SP: Companhia Editora Nacional, 1977.

VIEIRA, S. L. e FARIAS I. M. S. de. Política educacional no Brasil: introdução histórica. 3 ed. Brasília: Liber Livro Editora, 2011.

Recebido em: 01/10/2021

Aprovado em: 25/10/2021

Publicado em: 28/10/2021 